\title{
Article \\ The Effect of Cooling Rate on the Microstructure Evolution and Mechanical Properties of Ti-Microalloyed Steel Plates
}

\author{
Xiaolin $\mathrm{Li}^{1}{ }^{1, * \mathbb{D}}, \mathrm{Qian} \mathrm{Li}^{1}{ }^{1}$, Haozhe $\mathrm{Li}^{1}{ }^{1}$, Xiangyu Gao ${ }^{2}$, Xiangtao Deng ${ }^{3, *}$ and Zhaodong Wang ${ }^{3}$ \\ 1 Center of Advanced Lubrication and Seal Materials, State Key Laboratory of Solidification Processing, \\ Northwestern Polytechnical University, Xi'an 710072, China; liqian0410@mail.nwpu.edu.cn (Q.L.); \\ lihaozhe@mail.nwpu.edu.cn (H.L.) \\ 2 Analytical \& Testing Center, Northwestern Polytechnical University, Xi'an 710072, China; \\ tsgxgaoxiangyu@nwpu.edu.cn \\ 3 State Key Laboratory of Rolling and Automation, Northeastern University, Shenyang 110819, China; \\ zhdwang@mail.neu.edu.cn \\ * Correspondence: xiaolinli@nwpu.edu.cn (X.L.); dengxt@mail.neu.edu.cn (X.D.)
}

Citation: Li, X.; Li, Q.; Li, H.; Gao, X.; Deng, X.; Wang, Z. The Effect of Cooling Rate on the Microstructure Evolution and Mechanical Properties of Ti-Microalloyed Steel Plates. Materials 2022, 15, 1385. https:// doi.org/10.3390/ma15041385

Academic Editors: Abílio M.P. De Jesus and Andrea Di Schino

Received: 21 January 2022

Accepted: 9 February 2022

Published: 13 February 2022

Publisher's Note: MDPI stays neutral with regard to jurisdictional claims in published maps and institutional affiliations.

Copyright: (C) 2022 by the authors. Licensee MDPI, Basel, Switzerland. This article is an open access article distributed under the terms and conditions of the Creative Commons Attribution (CC BY) license (https:// creativecommons.org/licenses/by/ $4.0 /$ )

\begin{abstract}
Ti-bearing microalloyed steel plates with a thickness of $40 \mathrm{~mm}$ were subjected to ultra-fast cooling (UFC) and traditional accelerate cooling after hot-rolling, aiming to investigate the effect of cooling rate on the microstructure and mechanical properties homogeneity, and thus obtain thick plates with superior and homogeneous mechanical properties. Yield strength, tensile strength, and elongation were $642 \mathrm{MPa}, 740 \mathrm{MPa}, 19.2 \%$ and $592 \mathrm{MPa}, 720 \mathrm{MPa}$ and $16.7 \%$, respectively, in the surface and mid-thickness of the steel with ultra-fast cooling, while in the steel with traditional accelerate cooling, $535 \mathrm{MPa}, 645 \mathrm{MPa}, 23.4 \%$ and $485 \mathrm{MPa}, 608 \mathrm{MPa}, 16.2 \%$ were obtained in the surface and mid-thickness of the plate. The yield strength has been greatly improved after UFC, for the refinement of grain and precipitates produced by UFC. In addition, the equivalent grain size and precipitates size in the thick plate with UFC are homogeneous in the thickness direction, leading to uniform mechanical properties. The crystallographic characteristics of different precipitates have been studied. The precipitates formed in the austenite deformation stage obey Kurdjumov-Sachs orientation relationship with the ferrite matrix, while the fine precipitates formed in the ferrite obey $[112]_{\mathrm{MC}} / /[110]_{\alpha}$ and $(\overline{11} 1)_{\mathrm{MC}} / /(\overline{112})_{\alpha}$ orientation relationship with the ferrite matrix.
\end{abstract}

Keywords: thermomechanical controlled processing (TMCP); ultra-fast cooling system; microstructure evolution; precipitation behavior; mechanical properties

\section{Introduction}

During recent decades, the adjustment and upgrade of steel products have always been essential tasks in the iron and steel industry under the pressure with respect to resources, energy, and environment. Therefore, it is essential to propose an effective way to strengthen the microalloyed steel and make the microalloyed steel develop continuously and positively. Funakawa in JFE Corporation developed an automobile steel with a yield strength of $780 \mathrm{MPa}$. The steel was strengthened by the addition of Ti and Mo elements, and the microstructure of the steel was ferrite with high density randomly distributed nano-precipitates [1]. Besides microalloying, the thermomechanical controlled processing (TCMP) technique has also been proposed and studied extensively. Wang and his group at Northeastern University studied the effect of TMCP parameters, including hot-rolling temperature [2,3], cooling rate [3], and finish cooling temperature [4-6], on the mechanical properties of medium thickness microalloyed steel plates. Nishioka published a review describing the metallurgical aspects of the microalloying in steel, and discussing the advantages of TMCP, for example, in terms of weldability, which is reduced upon alloying [7]. Even though extensive studies have been performed on the medium thickness plate, the research on the thick steel plate is still limited. 
Advanced thick steel plates are important structural materials for ship hulls, pressure vessels, bridges, buildings, and offshore structures [8-11]. The general trend for them is achieving higher strength and maintaining or improving other properties simultaneously, and also guaranteeing homogeneity in thickness. TMCP technology is a simple and cost-effective method to enhance the properties of steel [12-14], which was first reported in Japan. Uemori et al. [15] in Nippon Steel Co., reported that the yield strength of microalloyed heavy steel plates can increase by $300 \mathrm{MPa}$ compared with the traditional quenching-tempering steel. While in TMCP of advanced heavy steel plates, the deformation and cooling are rarely uniform over the entire thickness, which then leads to inhomogeneous microstructure and mechanical properties being obtained in the plate. Thus, In order to enhance the homogeneity of the heavy steel plate, expensive elements, such as $\mathrm{Ni}, \mathrm{Cr}$, $\mathrm{Mo}$, and $\mathrm{Cu}$ were added to improve the hardenability of the steel plate [16-18]. Although a satisfactory strength-toughness combination is obtained in the steel plate arising from the combined effect of refined ferrite grain size and precipitation strengthening, the weldability is still a tough problem that needs to be overcome due to the enhanced carbon equivalent by the addition of expensive microalloying elements. So, the technique should be developed to increase the homogeneity of the thick steel plate instead of adding too many hardenability elements.

Based on the above problem, new generation TMCP (NG-TMCP), that is TMCP involving ultrafast cooling (UFC) technology, is currently being applied to industrial production [19-21], aiming to reduce the consumption of expensive alloying elements, improve the homogeneity of the steel plate, and make the steel making process economically visible [15,22-24]. The cooling medium for UFC is water, and the finish cooling temperature was controlled by changing the pressure and density of the water outlet, which was determined by the automatic control system. The principle of the UFC device is to reduce the aperture of the water outlet, densify the water outlet and increase the water pressure, to ensure that the water flow has enough energy and impact force to break the water film. In addition, NG-TCMP can greatly suppress the degree of the alloys precipitated in austenite and increase the supersaturating in ferrite or bainite, improving the precipitation hardening. Thus, it is of practical significance to evaluate the effect of UFC after hot-rolling on the microstructural and mechanical properties homogeneity in heavy steel plates.

In the present work, we focus on comparing the effect of UFC and traditional accelerated cooling on the homogeneity of microstructure and mechanical properties of thick plates, and investigate the correlation between microstructure and mechanical properties. Furthermore, the precipitation behavior in different regions of the thick plate is also studied, with a particular focus on the crystallographic characteristic.

\section{Materials and Methods}

\subsection{Materials and Thermo-Mechanical Processing}

The chemical composition of the investigating steel is listed in Table $1.0 .08 \%$ Ti was added to the composition of traditional Q345 grade steel. The steel was melted, cast, and then rolled into plates with NG-TMCP and traditional TMCP technologies. The detailed processing is as follows: the steel ingot was isothermally held at $1250{ }^{\circ} \mathrm{C}$ for $2 \mathrm{~h}$ to dissolve the inclusions formed in the casting stage, and then hot-rolled to $40 \mathrm{~mm}$ with a thickness reduction of $60 \%$. Next, the steels were cooled to $\sim 590{ }^{\circ} \mathrm{C}$ with ultra-fast cooling and traditional cooling, and held for 20 min (hereafter referred to steel A and B). Finally, the steels were air-cooled to room temperature. The schematic diagram in Figure 1 illustrates the difference between NG-TMCP and traditional TMCP, and the detailed parameters of the processing are given in Table 2.

Table 1. The chemical composition of the experimental steel in this study (wt.\%).

\begin{tabular}{ccccccccc}
\hline $\mathbf{C}$ & $\mathbf{M n}$ & $\mathbf{S i}$ & $\mathbf{A l}$ & $\mathbf{T i}$ & $\mathbf{P}$ & $\mathbf{S}$ & $\mathbf{N}$ & $\mathbf{O}$ \\
\hline 0.15 & 0.98 & 0.28 & 0.02 & 0.08 & 0.015 & 0.005 & $27 \mathrm{ppm}$ & $48 \mathrm{ppm}$ \\
\hline
\end{tabular}




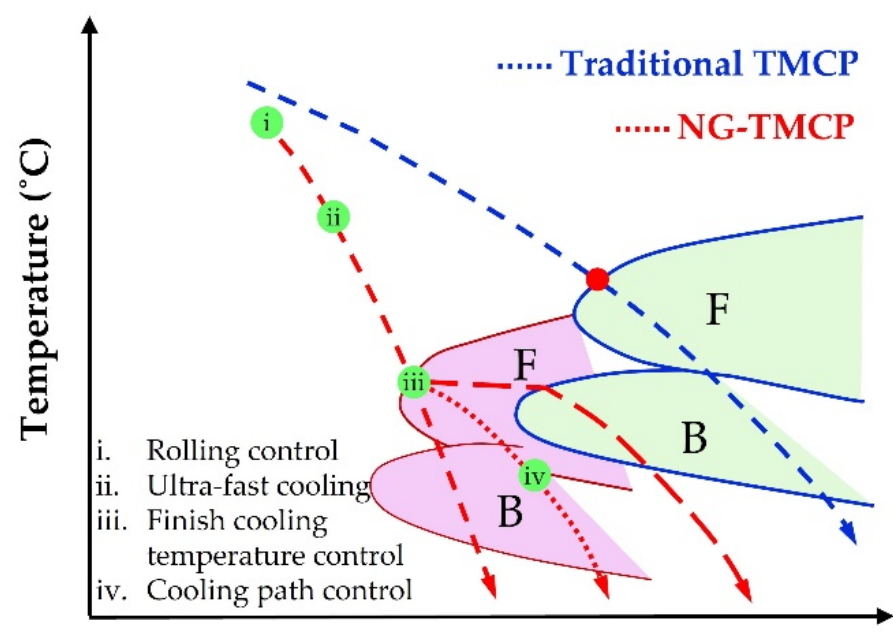

Time in logarithm (s)

Figure 1. Schematic diagram showing the difference between NG-TMCP and traditional TMCP. F stands for ferrite, and B stands for bainite in this figure.

Table 2. Thermal mechanical processing parameters of the tested steels.

\begin{tabular}{|c|c|c|c|c|c|c|c|}
\hline \multirow[t]{2}{*}{ No. } & \multicolumn{2}{|c|}{$\operatorname{RTG}^{1}\left({ }^{\circ} \mathrm{C}\right)$} & \multicolumn{2}{|c|}{$\mathrm{NRTG}^{2}\left({ }^{\circ} \mathrm{C}\right)$} & \multirow{2}{*}{ Cooling Rate, ${ }^{\circ} \mathrm{C} / \mathrm{s}$} & \multirow{2}{*}{$\mathrm{FCT}^{3},{ }^{\circ} \mathrm{C}$} & \multirow{2}{*}{ Type of Cooling } \\
\hline & Start & Finish & Start & Finish & & & \\
\hline A & 1150 & 1091 & 880 & 875 & $60(45)$ & $590(621)$ & $20 \mathrm{~min}$, air cooling \\
\hline B & 1150 & 1096 & 889 & 864 & $10(5.8)$ & $598(678)$ & $20 \mathrm{~min}$, air cooling \\
\hline
\end{tabular}

${ }^{1}$ RTG: recrystallization temperature region. ${ }^{2}$ NRTG: non-recrystallization temperature region. ${ }^{3}$ FCT: finish cooling temperature.

\subsection{Microstructural Characterization}

The specimens for microstructure characterization were cut from the hot-rolled plates, and then mechanically ground with sandpapers possessing different roughness in order to meet the surface quality before etching. The optical micrograph (OM; Olympus, Tokyo, Japan) and scanning electronic micrograph (SEM) specimens were etched with $4 \%$ nital solution by volumeat room temperature, and conducted by Zeiss Ultra 55 SEM (Oberkochen, Baden-Württemberg, Germany). For electron backscattered diffraction (EBSD; Oberkochen, Baden-Württemberg, Germany) detections, the specimens were electrochemically polished in a solution consisting of $650 \mathrm{~mL}$ ethyl alcohol, $100 \mathrm{~mL}$ perchloric acid, and $50 \mathrm{~mL}$ distilled water. TEM characterizations were carried out by FEI Tecnai G² F20 TEM (Hillsboro, OR, USA) equipped with an energy-dispersive $\mathrm{X}$-ray (EDX) spectrometer at an accelerating voltage of $200 \mathrm{kV}$. The specimens were cut from the steel plates and mechanically thinned to $\sim 0.06 \mathrm{~mm}$. Then the foils were electrochemically jet polished at $-30{ }^{\circ} \mathrm{C}$ in a solution containing 9 vol.\% Perchloric acid in ethanol.

The TEM technique was used to investigate the category, crystal structure, and lattice parameter of the precipitates. A detailed description of the method has been listed in previously published papers [4]. In addition, Crystal Maker software was used for the simulation of the unit cell structure to clearly present the orientation relationship between the precipitates and ferrite matrix.

\subsection{Hardness and Tensile Tests}

The hardness was tested by a Vickers hardness tester with a working load of $1 \mathrm{~N}$ and a dwelling time of $10 \mathrm{~s}$, and each sample was tested at least five times. Cylindrical tensile test specimens with a diameter of $5 \mathrm{~mm}$ and a gauge length of $25 \mathrm{~mm}$ were prepared from the surface and mid-thickness of the thick steel plates perpendicular to the rolling direction and the specimens are parallel with the plate. The tensile test was conducted in SANS-5000 
(Zhejiang, China) tensile tester with a rate of $1 \mathrm{~mm} / \mathrm{min}$. The impact toughness test was conducted in Instron 9250 impact tester (Norwood, MA, USA), and the Standard Charpy $\mathrm{v}$-notch impact sample was chosen with a dimension of $10 \times 10 \times 55 \mathrm{~mm}^{3}$, which were prepared along the rolling direction to determine impact toughness at -20 and $-40{ }^{\circ} \mathrm{C}$.

\section{Results and Discussion}

\subsection{Microstructural Evolution}

Figure 2 presents the microstructure of the specimens obtained from the surface and mid-thickness of steel A. The microstructure in the surface region primarily consists of lath bainite (LB) and polygonal ferrite (PF), together with a little dark-etched pearlite (P), as shown in Figure 2a,b. TEM micrograph in Figure 2c indicates upper bainite structure for some thin cementite located within ferrite laths, indexed by the selected area electronic diffraction (SAED) pattern in Figure $2 c$. Figure $2 d-f$ illustrates the microstructure in the mid-thickness region. The microstructure consists of PF, $\mathrm{P}$, acicular ferrite (AF), and the corresponding percentage were $\sim 89 \%, \sim 8 \%$, and $\sim 3 \%$, respectively. Figure $2 \mathrm{f}$ shows the TEM image of PF and P. High-density dislocations located in PF and pearlitic ferrite. The lamellar cementite locates in ferrite laths in pearlite and the interlamellar spacing is $\sim 200 \mathrm{~nm}$.
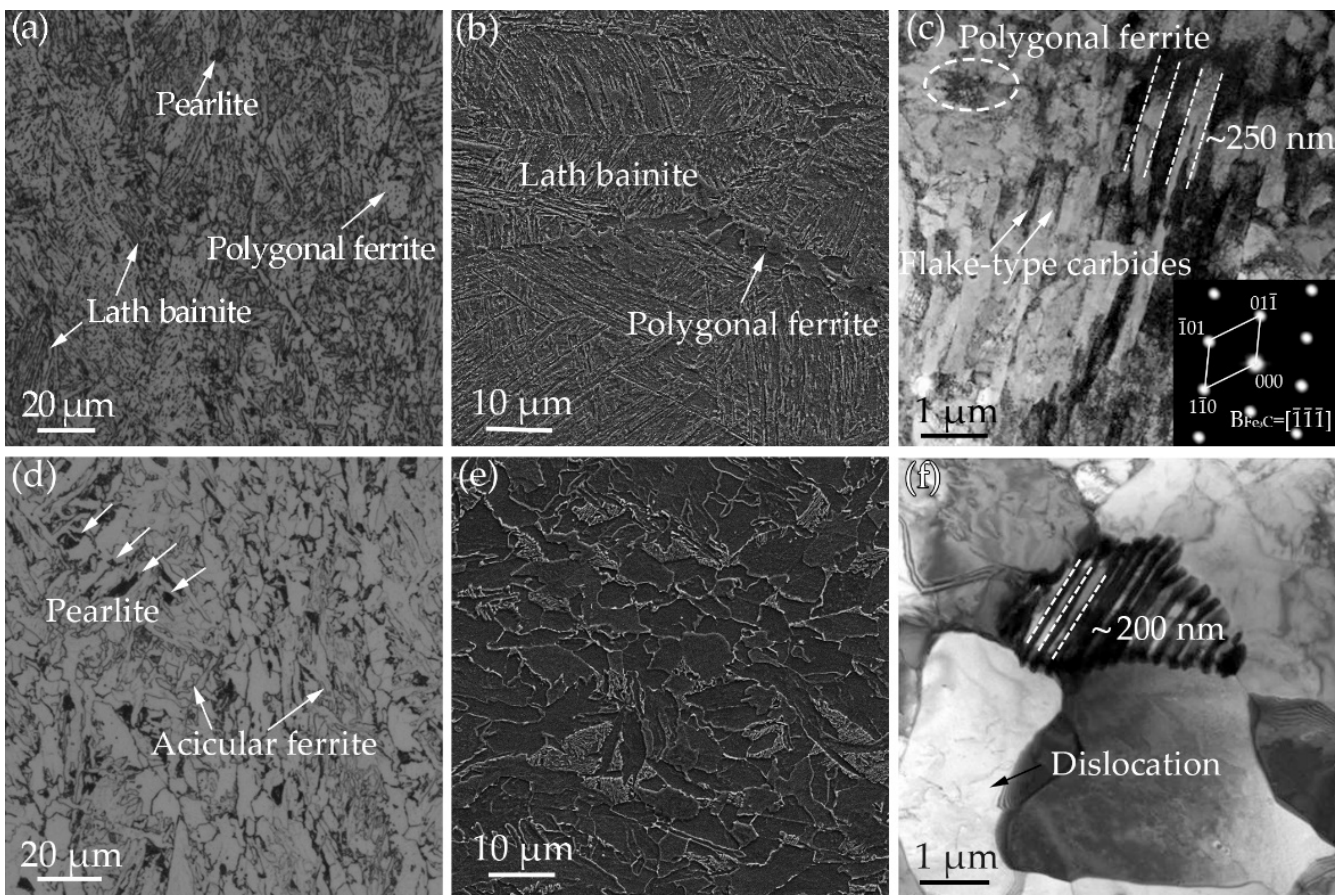

Figure 2. (a,d) OM images; (b,e) SEM images and (c,f) TEM images of the specimens obtained from surface and mid-thickness of in steel A plate.

Figure 3 shows the microstructure of the specimens obtained from the surface and mid-thickness region of steel $\mathrm{B}$. The microstructure in the surface region consists of AF and PF, with a small amount of dark-etched P (Figure 3a). EDSD results indicate that there is no obvious texture in the microstructure, and the average grain size is $13.2 \mu \mathrm{m}$ (Figure 3b). Figure 3c shows the corresponding TEM image, PF and AF lath can be observed, accompanied by extensive dislocations in AF lath. In order to clearly observe the dislocations, a two-beam diffraction method with the $g=(002)$ has been used, as shown in Figure 3d. Figure $3 \mathrm{e}-\mathrm{h}$ shows the microstructure in the mid-thickness region. The microstructure mainly consists of PF and P. The average size of the grain is $18.6 \mu \mathrm{m}$, as shown in Figure 3e, f. Figure 3g, h present the TEM images of PF. Extensive dislocation has been observed with $g=(110)$. The grain size in the mid-thickness region is larger compared with that in the surface of the plate, which reveals obvious inhomogeneity in 
the microstructure of steel B. The inhomogeneity in microstructure can be attributed to different finish cooling temperatures and cooling rates. In the mid-thickness of the plate, no AF has been observed due to the lower undercooling, and a large amount of pearlite formed by the relatively lower cooling rate.
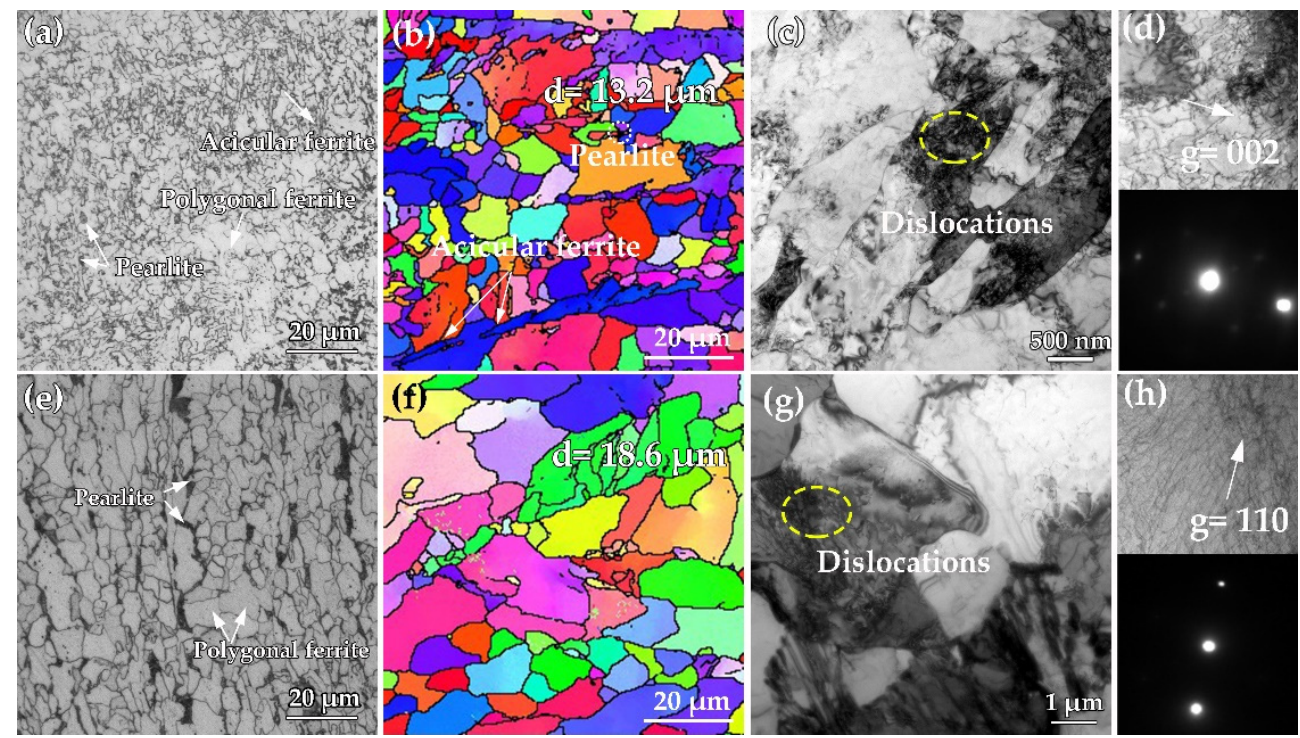

Figure 3. Microstructure analysis of the specimens obtained from the surface and mid-thickness region of steel B. (a,e) OM images; (b,f) EBSD micrographs; (c,g) TEM images; $(\mathbf{d}, \mathbf{h})$ the enlargement view of yellow circle in $(\mathbf{c}, \mathbf{g})$ showing the dislocations observed by two-beam diffraction methods in different vectors.

\subsection{Mechanical Properties}

Figure 4 presents the hardness distribution along the thickness direction in steel A and $B$. In steel $A$, the hardness at surface, $1 / 8,1 / 4,3 / 8$ and $1 / 2$ thickness is $267,256,246$, 239 , and $235 \mathrm{HV}$, respectively. While in steel B, the hardness is $229,211,198,186,179 \mathrm{HV}$, respectively. The hardness decreases with the increase of distance to the surface in both steels, which means that the hardness in the surface region is higher compared with that in the mid-thickness region. The hardness difference for the surface and mid-thickness region is $38 \mathrm{HV}$ and $50 \mathrm{HV}$ in steels $\mathrm{A}$ and $\mathrm{B}$, respectively. It is visible that the hardness is more homogeneous in steel A, compared with that in steel B.

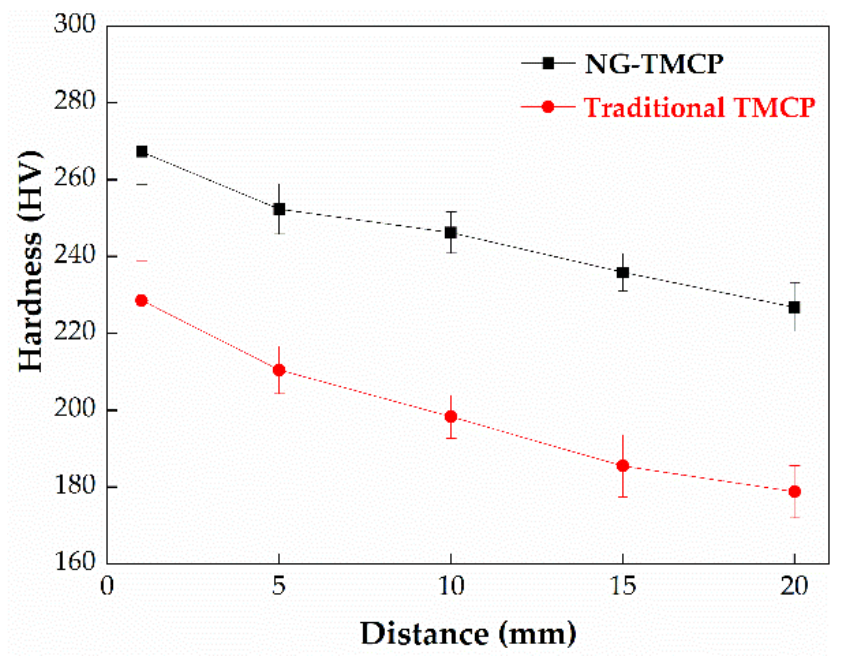

Figure 4. Vickers hardness evolution from the surface to the center part. 
The mechanical properties of steel A and B are listed in Table 3, with the data obtained from three specimens. The tensile stress-strain curves of specimens in the surface and mid-thickness regions of steel A and B are presented in Figure 5. In Figure 5a, obvious yield platform in tensile strain-stress curve has observed both in the surface and mid-thickness region of steel $A$, while continuous yielding behavior observed in steel B (Figure 5b). In steel $\mathrm{A}$, the yield strength, tensile strength, and elongation for the surface and mid-thickness region are $642 \mathrm{MPa}, 740 \mathrm{MPa}, 19.2 \%$, and $592 \mathrm{MPa}, 720 \mathrm{MPa}, 17.3 \%$ respectively; and in steel $\mathrm{B}$ are $535 \mathrm{MPa}, 645 \mathrm{MPa}, 23.4 \%$ in surface region and $485 \mathrm{MPa}, 608 \mathrm{MPa}, 16.2 \%$ in the mid-thickness region. In both steels, the strength decreases with the increase in distance to the surface.

Table 3. Mechanical properties obtained from the surface and mid-thickness of steel A and B plates.

\begin{tabular}{|c|c|c|c|c|c|c|c|}
\hline \multirow{2}{*}{\multicolumn{2}{|c|}{ Steel }} & \multirow{2}{*}{ Yield Strength, MPa } & \multirow{2}{*}{ Tensile Strength, MPa } & \multirow{2}{*}{ Elongation, \% } & \multirow{2}{*}{ Yield Ratio } & \multicolumn{2}{|c|}{ Impact Toughness, J } \\
\hline & & & & & & $-20^{\circ} \mathrm{C}$ & $-40^{\circ} \mathrm{C}$ \\
\hline \multirow[b]{2}{*}{ A } & $S^{1}$ & $642(5.2)$ & $740(6.1)$ & $19.2(1.3)$ & $0.87(0.2)$ & $88.9(3.6)$ & $68.9(5.4)$ \\
\hline & $\mathrm{M}^{2}$ & $592(5.7)$ & $720(5.9)$ & $17.3(1.8)$ & $0.82(0.2)$ & $75.3(2.8)$ & $55.8(5.1)$ \\
\hline \multirow{2}{*}{ B } & $S$ & $558(2.8)$ & $645(2.1)$ & $23.4(0.9)$ & $0.86(0.1)$ & $55.6(5.6)$ & $30.6(6.2)$ \\
\hline & $\mathrm{M}$ & $515(4.3)$ & 608 (4.9) & $16.2(1.2)$ & $0.85(0.1)$ & $45.2(4.2)$ & $28.2(8.1)$ \\
\hline
\end{tabular}

${ }^{1} \mathrm{~S}$ represents the surface of the steel plate. ${ }^{2} \mathrm{M}$ represents the center thickness of the steel plate.

\section{(a)}

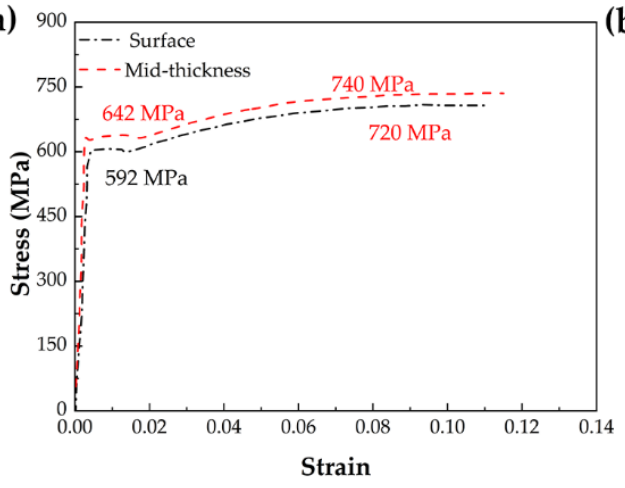

(b)

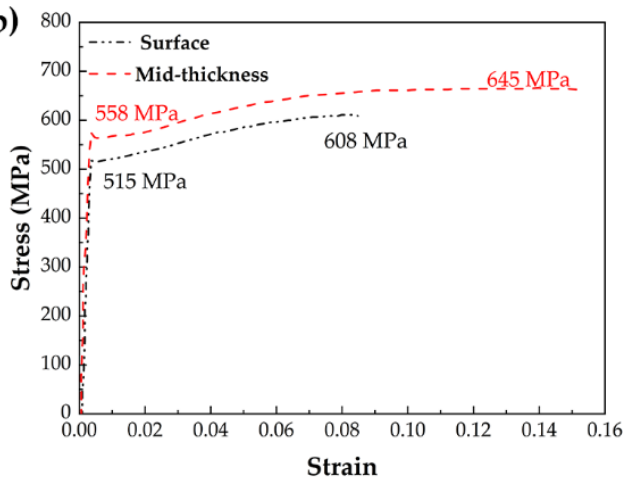

Figure 5. Tensile stress-strain curves of specimens obtained from surface and mid-thickness of steels A and B. (a) Tensile stress-strain curves of steel A; (b) Tensile stress-strain curves of steel B.

In steel $\mathrm{A}$, the impact energy at $-20^{\circ} \mathrm{C}$ and $-40{ }^{\circ} \mathrm{C}$ is $88.9 \mathrm{~J}$ and $68.9 \mathrm{~J}$ in the surface, while in the mid-thickness, the impact energy at $-20^{\circ} \mathrm{C}$ and $-40{ }^{\circ} \mathrm{C}$ is $75.3 \mathrm{~J}$ and $55.8 \mathrm{~J}$, respectively. In steel $\mathrm{B}$, the impact energy at $-20{ }^{\circ} \mathrm{C}$ and $-40{ }^{\circ} \mathrm{C}$ is $55.6 \mathrm{~J}$ and $30.6 \mathrm{~J}$ in the surface, while in the mid-thickness, the impact energy at $-20^{\circ} \mathrm{C}$ and $-40{ }^{\circ} \mathrm{C}$ is $45.2 \mathrm{~J}$ and $28.2 \mathrm{~J}$, respectively. The impact energy decreases with the decrease in tested temperature and is higher in the surface compared with that in the mid-thickness region.

In order to analyze the fracture mechanism, the tensile fracture and impact fracture have been observed in both steels. Figure 6 shows the SEM fractography of tensile fractures in the surface region of steel A and B. The failure mode in both steels exhibit a "cup-cone" type of fracture, and three zones (fibrous, radial, shear lip) can be observed, indicating the fracture mode is ductile fracture. Compared to that in steel $\mathrm{B}$, the fibrous zone is relatively larger, as indexed by the dashed ellipses in Figure 6a,e. The higher magnification of the fibrous zone is presented in Figure $6 \mathrm{~b}, \mathrm{f}$. Extensive dimples can be observed, accompanied by some micro-pores and macro-cracks. In this region, the deformation is uniform, corresponding to the uniaxial stress state condition. Figure $6 c, g$ present the higher magnification of the radial region. The cleavage facets have been observed, and the crack propagation direction can be confirmed. In this period, the cracks lose their stability and propagate quickly. In most parts of the shear lip zones, the angle between the shear lip zone and axial direction is $45^{\circ}$. This characteristic is indicative of combined normal and shear separation. Part of the shear-lip rim in Figure 6 a,e is larger than $45^{\circ}$, suggesting that crack deviation 
is random in different directions [14]. The enlargement view of the shear lip zone in both steels is presented in Figure $6 \mathrm{~d}, \mathrm{~h}$. The dimples are flat and stretched, and the dimples in steel A are relatively shallow compared with that in steel $\mathrm{B}$. The particles located in the dimples can be observed, and the composition of the particles is $\mathrm{TiC}$, as presented in the inset of Figure 6h.
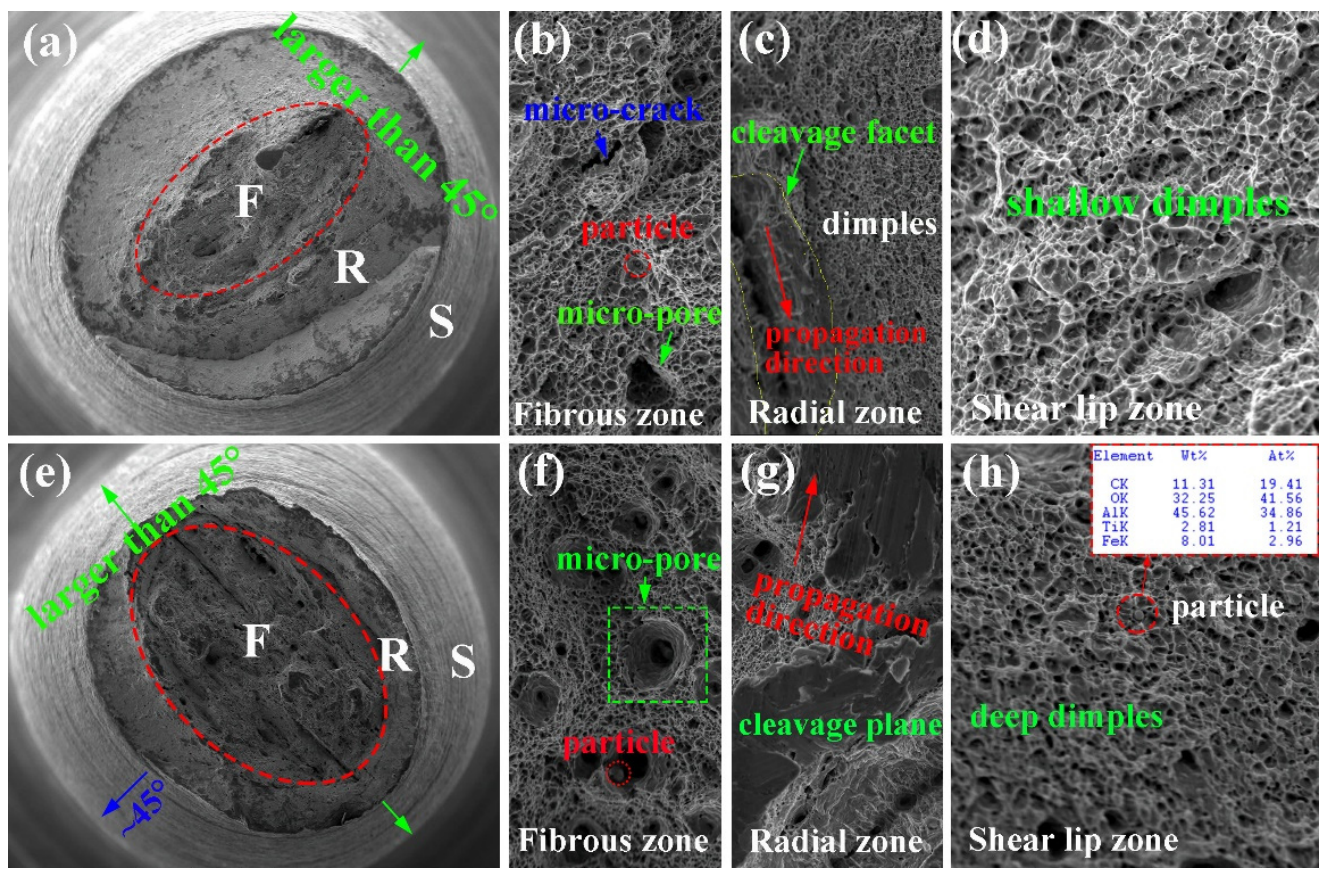

Figure 6. SEM micrographs of the tensile fracture of the specimen in the surface of steel A and B. $(\mathbf{a}, \mathbf{e})$ low magnification of the fracture, F stands for fibrous, R stands for radial, and S stands for shear lip; (b,f) high magnification of fibrous zone; $(\mathbf{c}, \mathbf{g})$ high magnification of radial zone; $(\mathbf{d}, \mathbf{h})$ high magnification of shear lip zone.

The typical deflection-load curve of the Charpy impact specimen usually contains five stages $[14,25]$. The total absorbed energy includes $E_{1}, E_{2}$, and $E_{3}$, and refer to crack initiation energy, table crack propagation energy, and unstable fracture energy, respectively, as shown in Figure 7a. Figure 7b,c shows the deflection-load curve of the Charpy impact specimen obtained from the surface region of steel A and B tested at $-20{ }^{\circ} \mathrm{C}$. The total impact absorbed energy in steel A is $88.9 \mathrm{~J}$. The crack initiation energy and crack propagation energy are $37.6 \mathrm{~J}$ and $51.3 \mathrm{~J}$, respectively (Figure 7b), while in steel B, the total impact absorbed energy is $55.6 \mathrm{~J}$, and the crack initiation absorbed energy and crack propagation energy are $28.9 \mathrm{~J}$ and $26.7 \mathrm{~J}$ (Figure 7c). The main difference in the total absorbed energy should be attributed to the crack propagation energy $\left(E_{2}\right.$ and $\left.E_{3}\right)$. The relatively high crack propagation energy can be attributed to the fine bainite structure and the high-volume fraction of grain boundary in the surface of steel A, comparing that in steel B.
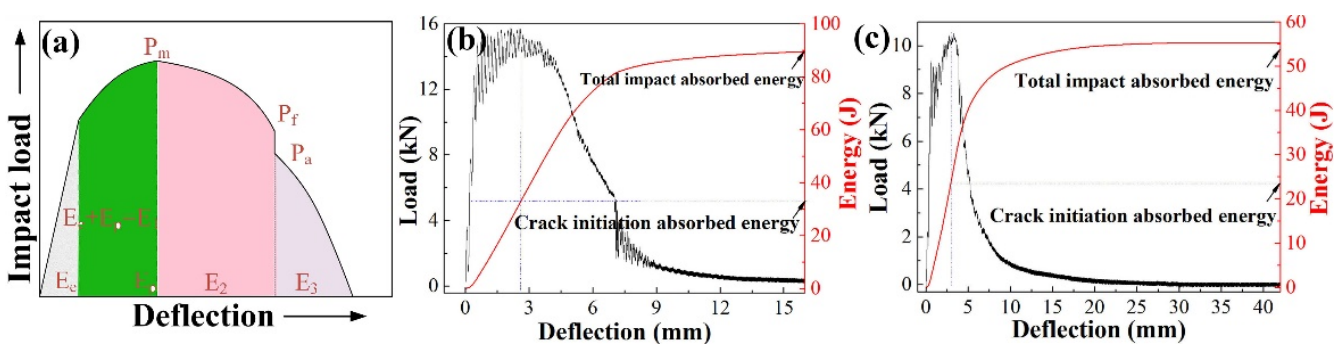

Figure 7. Schematic diagram (a) and deflection-load curves of the impact test specimen in steel A and $B(b, c)$. 
Figure 8 shows SEM fractography of the tensile test specimens obtained from the surface region of steel $\mathrm{A}$ and $\mathrm{B}$ at $-20^{\circ} \mathrm{C}$. The macrograph fracture morphology of steel A and B is shown in Figure 8a,d. Three regions can be observed, including fibrous, radial, shear lip zones ignoring the $\mathrm{V}$-notch zone, and the volume fraction of shear lip zone in steel $\mathrm{A}$ is higher compared to that in steel $\mathrm{B}$. In steel $\mathrm{A}$, tearing has been observed and in steel $\mathrm{B}$, the river pattern can be observed, which indicates that the impact toughness of steel A is higher compared with that in steel B. Figure $8 b$,e shows the fractography of the fibrous zone in both steel, dimples, and particles can be observed. Figure $8 \mathrm{c}$,f shows the fractography of the radial zone, referring to the crack propagation process. In this zone, the cracks propagate quickly, and the shear lip zone is produced after that the crack propagation is inhibited by plastic deformation. In general, the fibrous zone and shear lip zone can absorb higher impact energy compared to the radial zone. Therefore, the total absorbed energy in steel A should be higher compared with that in steel B for the higher volume fraction of fibrous and shear lip zones.
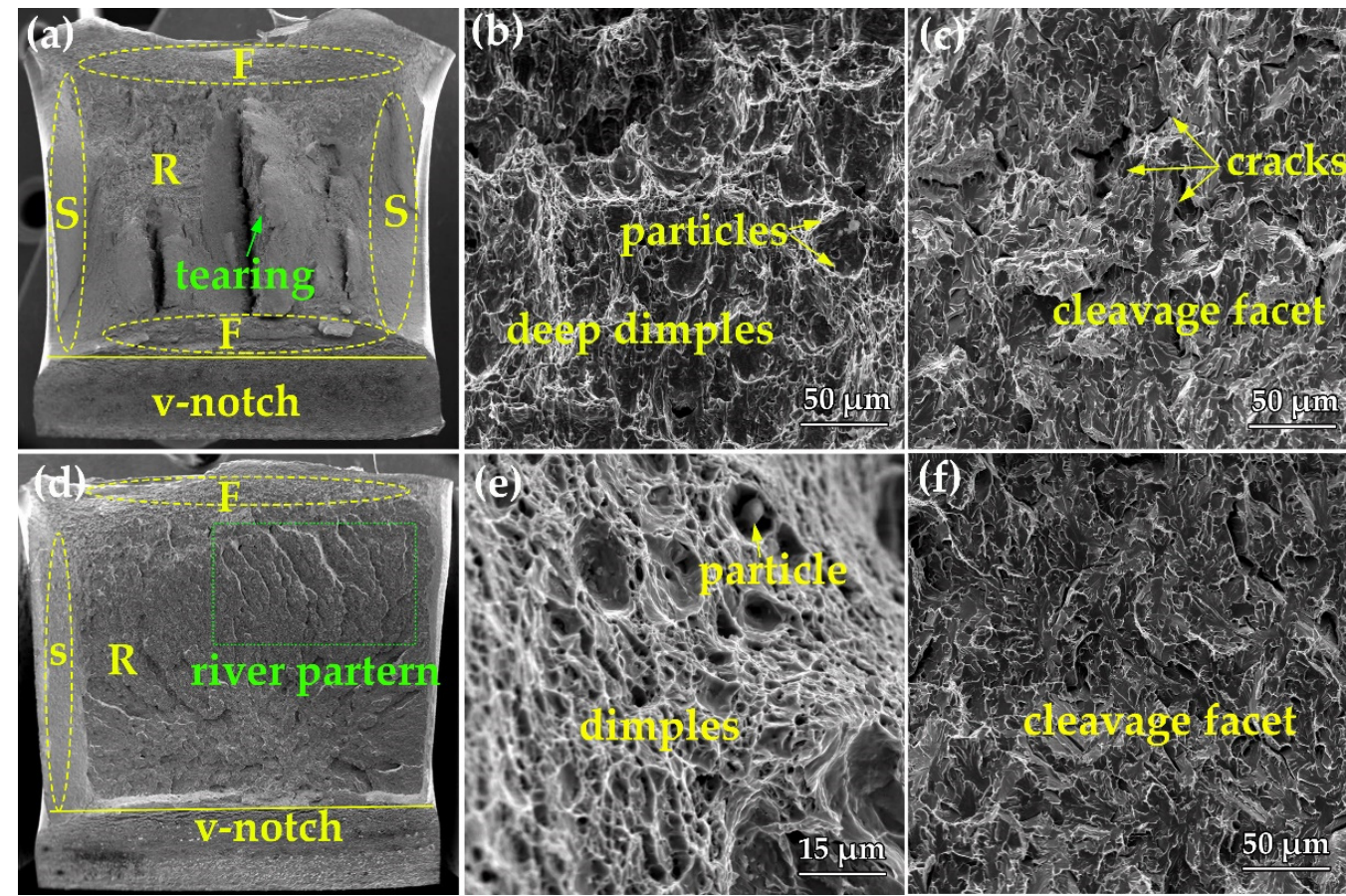

Figure 8. The impact fractography of the specimens obtained from the surface of steel A and B. $(\mathbf{a}, \mathbf{d})$ macrographs; $(\mathbf{b}, \mathbf{e})$ the fractography of shear lip zone; $(\mathbf{c}, \mathbf{f})$ the fractography of radial zone.

\subsection{Precipitation Behavior}

Figure 9 shows the TEM images of precipitates formed in the surface and mid-thickness steel A. Figure 9a shows the bright-field (BF) image of precipitates in PF in the surface. A large number of randomly distributed precipitates have been observed, and the average precipitate size is $\sim 3.5 \mathrm{~nm}$. The SAED pattern illustrated in Figure $9 \mathrm{~b}$ shows ferrite matrix with [110] direction and precipitates with [112] direction. The result indicates that the precipitates have a $\mathrm{NaCl}$ crystal structure, and the lattice parameter of these precipitates is roughly $0.432 \mathrm{~nm}$, which is close to the lattice parameter of TiC. It can also be concluded from the SAED pattern that these precipitates obey $[112]_{\mathrm{MC}} / /[110]_{\alpha}$ and $(\overline{11} 2)_{\mathrm{MC}} / /(\overline{1} 12)_{\alpha}$ orientation relationship with the ferrite matrix, which is different from the previously reported ones, such as BN and NW orientation relationship. Figure 8c illustrates the TEM image of precipitates formed in the mid-thickness of steel A plate. There are two size ranges of precipitates, and the large precipitates in the size range of 15-20 nm were assumed to be strain-induced during hot-rolling, while the tiny precipitates in the size range of 3-8 nm, were assumed to form in the cooling process. The precipitates are relatively larger compared with that in the surface region. 

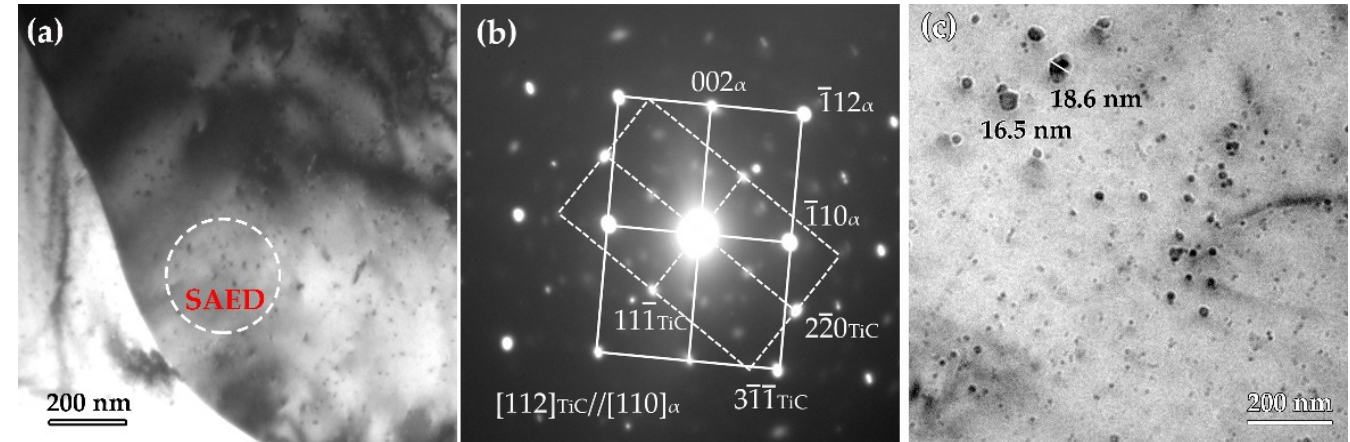

Figure 9. TEM images of precipitates formed in steel A. (a) precipitates in surface region; (b) SAED pattern, (c) precipitates in mid-thickness region.

In order to clearly illustrate the new orientation relationship observed in Figure 9. The structure of TiC and ferrite phases were put into the Crystal Maker software for simulation purposes, as shown in Figure 10. Figure 10a,c presents the simulated $\mathrm{TiC}$ and ferrite unit cells with the indexed plane of $(\overline{111})_{\text {Tic }}$ and $(\overline{112})_{\text {ferrite }}$. Figure $10 \mathrm{~b}, \mathrm{~d}$ shows the atom distribution of TiC and ferrite in the zone axis of $[112]_{\text {Tic }}$ and $[110]_{\text {ferrite }}$, together with the indexing of $(\overline{11} 1)_{\text {Tic }}$ and $(\overline{1} 12)_{\text {ferrite }}$ planes. The simulation results reveal the orientation relationship intuitively.

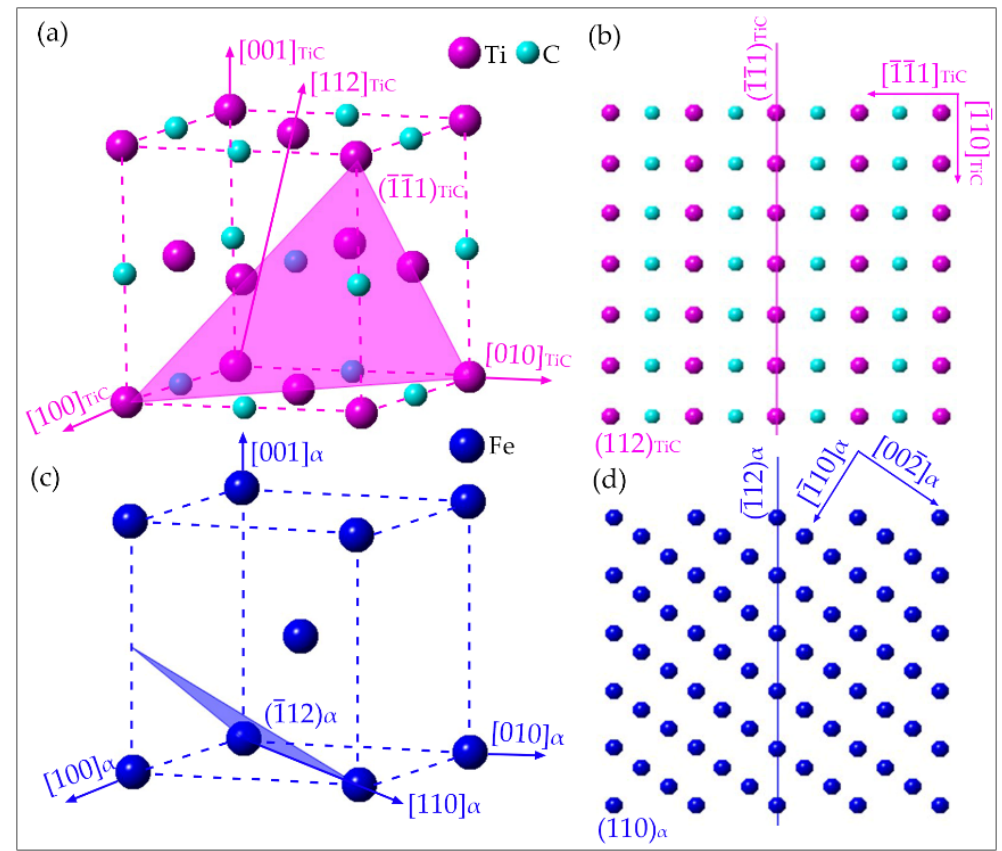

Figure 10. Simulation result of the new orientation relationship by Crystal Maker software. (a) unit cell of TiC with the indexing of $(\overline{11} 1)_{\text {Tic }}$ plane; (b) unit cell of ferrite with the indexing of $(\overline{1} 12)_{\text {ferrite }}$ plane $(\mathbf{c}, \mathbf{d})$ atom distribution of $\mathrm{TiC}$ and ferrite in the zone axis of $[112]_{\text {Tic }}$ and $[110]_{\text {ferrite }}$.

In order to analyze the difference between those two kinds of precipitates, the HRTEM technique was used to analyze the orientation relationship between ferrite and precipitates. Figure 11a shows the HRTEM image of the relatively large precipitate in Figure 9c. The crystal structure and the orientation relationship were identified by a fast Fourier transformed (FFT) diffractogram, as illustrated in Figure 11b. It can be deduced that the precipitate obeys the Kurdjumov-Sachs (KS) orientation relationship with ferrite matrix, that is $[111]_{\text {ferrite }} / /[110]_{\mathrm{TiC}}$ and $(\overline{101})_{\text {ferrite }} / /(111)_{\mathrm{TiC}}[26,27]$. To our knowledge, austenite strain-induced precipitates adopt cube-on-cube orientation relationship with austenite, that is $[001]_{\text {ferrite }} / /[001]_{\mathrm{TiC}}$ and $(001)_{\text {ferrite }} / /(001)_{\mathrm{TiC}}$, when austenite is transformed into ferrite, the KS orientation relationship obeyed by austenite and ferrite will be inherited by 
the precipitate and ferrite $[28,29]$. Figure 11c,d illustrate the IFFT images of the precipitates and ferrite matrix, and the lattice parameter can be measured to be $0.286 \mathrm{~nm}$ and $0.432 \mathrm{~nm}$.
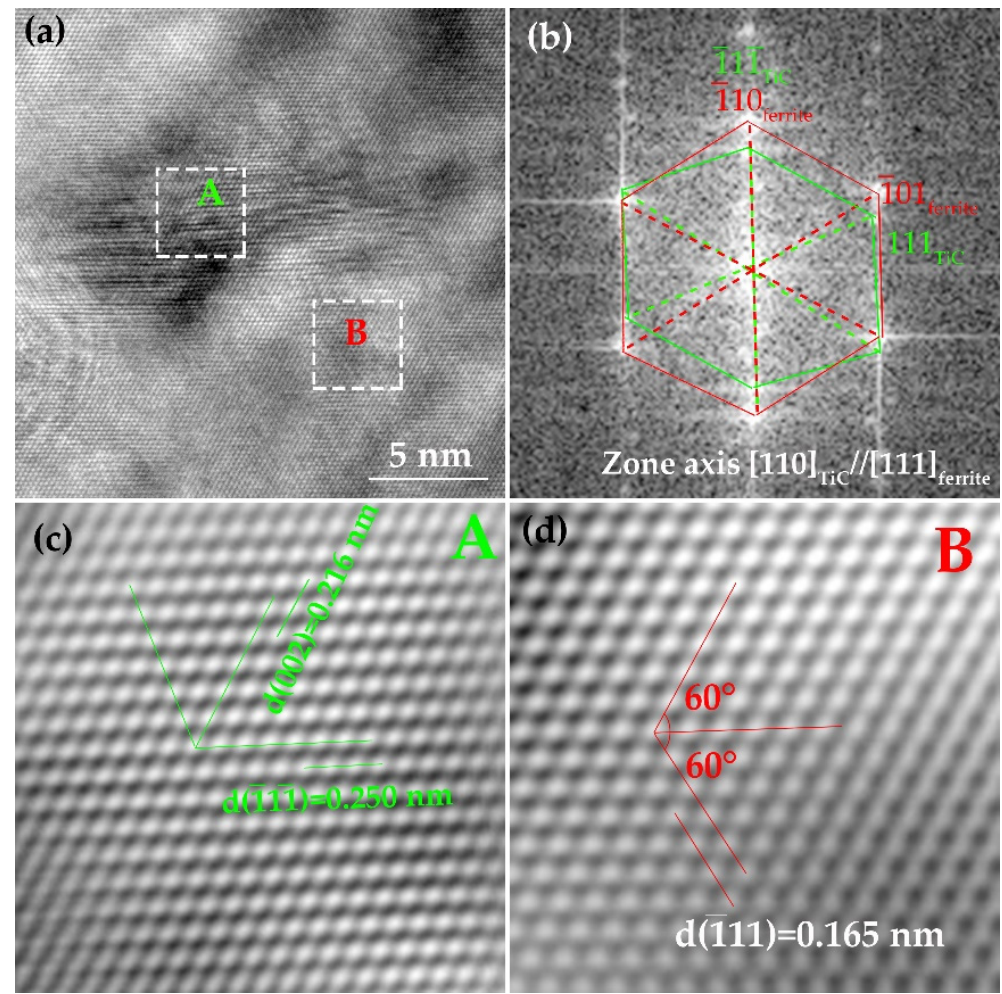

Figure 11. Crystallographic characterization of deformation-induced TiC formed in the mid-thickness of the plate in steel A. (a) HRTEM image; (b) FFT diffractogram; (c,d) IFFT of precipitate and matrix.

Figure 12 shows the TEM image of precipitates in the surface and mid-thickness of steel B. In the surface region of steel B, the precipitates are in the size range of 5-20 nm, while in the mid-thickness region, the precipitates are in the size range of $10-30 \mathrm{~nm}$, as shown in Figure 12a,b. The EDS result indicates that the precipitate is $\mathrm{TiC}$, as shown in Figure 12c.
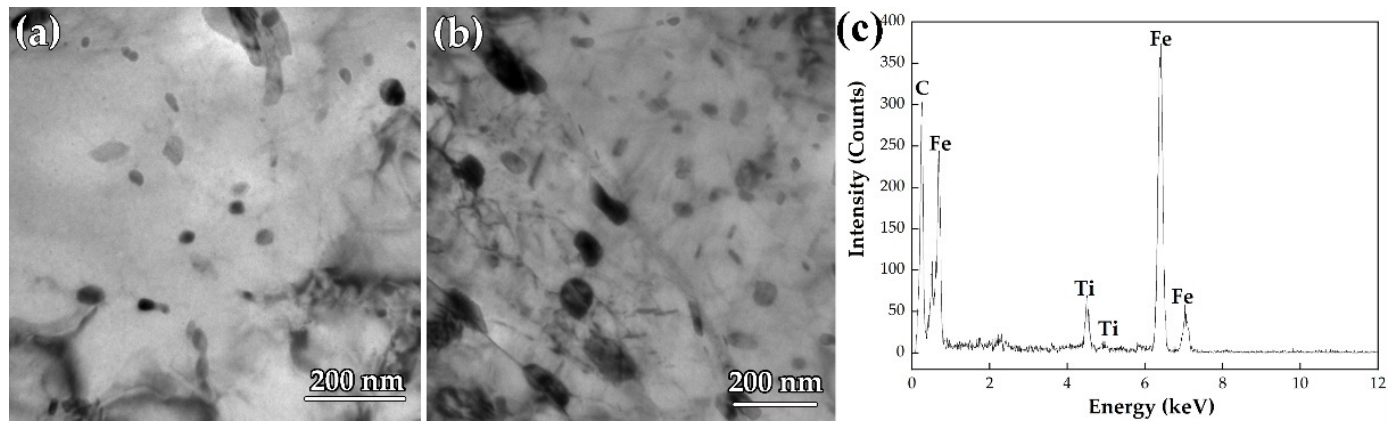

Figure 12. (a,b) TEM images of the precipitates obtained from surface and mid-thickness and (c) the corresponding EDS of steel B plate.

\subsection{Strengthening and Toughing Mechanism}

For low-carbon steel, the yield strength equals to the sum of solid strengthening, grain refinement strengthening, and precipitation strengthening, and is given by the following equation $[21,26]$.

$$
\begin{aligned}
& \sigma_{y}=\sigma_{S G}+\sigma_{S S}+\sigma_{S P} \\
& =600 D^{-1 / 2}+\{46[\mathrm{C}]+37[\mathrm{Mn}]+83[\mathrm{Si}]+59[\mathrm{Al}]+2918[\mathrm{~N}]+80.5[\mathrm{Ti}]\}+\sigma_{S P}
\end{aligned}
$$


where, $\sigma_{\mathrm{Y}}, \sigma_{\mathrm{SG}}, \sigma_{\mathrm{SS}}$, and $\sigma_{\mathrm{SP}}$ represent the yield strength, grain refinement strengthening, solid solution strengthening, and precipitation strengthening in $\mathrm{MPa}$, respectively. $D$ represents the average grain size. From Equation (1), the solid solution strengthening has been determined to be $\sim 80 \mathrm{MPa}$ and it is concluded that the main factors affecting yield strength are grain refinement strengthening and precipitation strengthening.

The precipitation hardening contribution to yield strength was estimated by AshbyOrowan [26]:

$$
\Delta \sigma=10.8 \frac{\sqrt{f}}{d} \ln (1630 d)
$$

where, $f$ is the volume fraction of precipitates and $d$ is the average radius of the precipitates. The precipitation strengthening in the surface and mid-thickness region of steel A was calculated to be $320.4 \mathrm{MPa}$ and $260.9 \mathrm{MPa}$, while in steel $\mathrm{B}$, the precipitation strengthening is $230.6 \mathrm{MPa}$ and $218 \mathrm{MPa}$.

In order to calculate the grain refinement strengthening, the equivalent grain size should be measured. Figure 13 illustrates the EBSD analysis of steel A, including grain size evaluation and grain boundary analysis, which determined the deflection of crack propagation, that is impact toughness. The grain size in the surface and mid-thickness region are $6.5 \mu \mathrm{m}$ and $7.3 \mu \mathrm{m}$, as shown in Figure 13a,c,e,g). Figure 13b,f shows the image quality map, the black lines mean high misorientation grain boundaries (HAGB, $\geq 15^{\circ}$ ), and red lines mean low misorientations grain boundaries (LAGB, $2-15^{\circ}$ ). The grain boundaries of AF and PF, packets, and blocks of LB exhibit HAGBs, while the laths inside the austenitic grains show LAGBs. The HAGB can effectively deflect the propagation of cleavage microcracks, whereas the LAGB have less ability to deflect the crack $[26,30]$. The fraction of HAGB in surface and mid-thickness are $57 \%$ and $39 \%$.
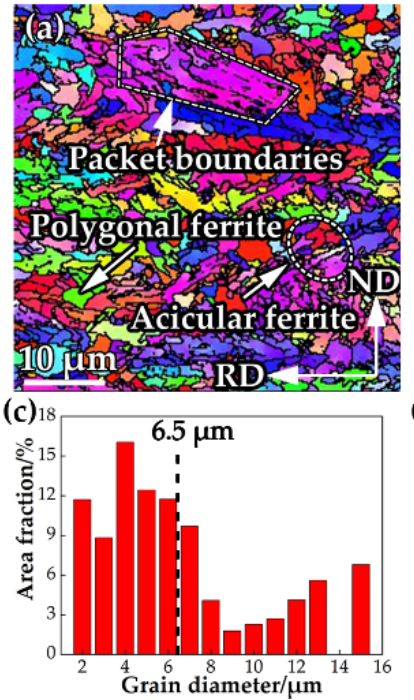
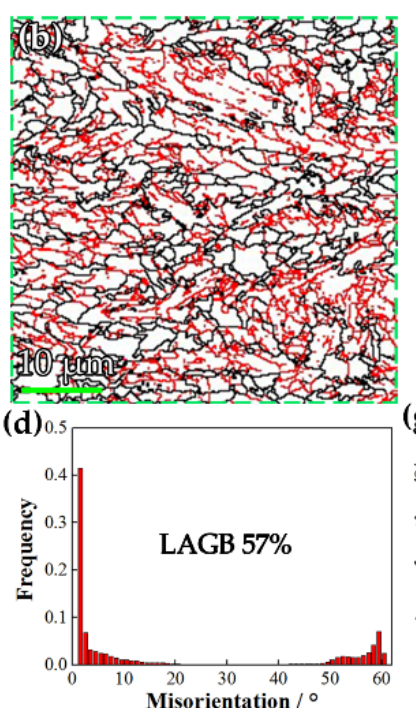
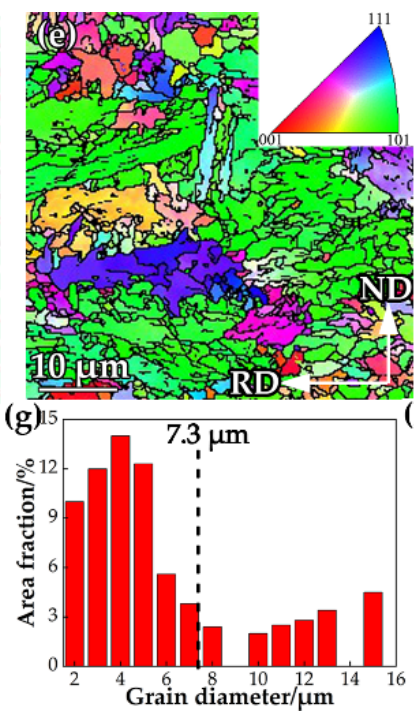
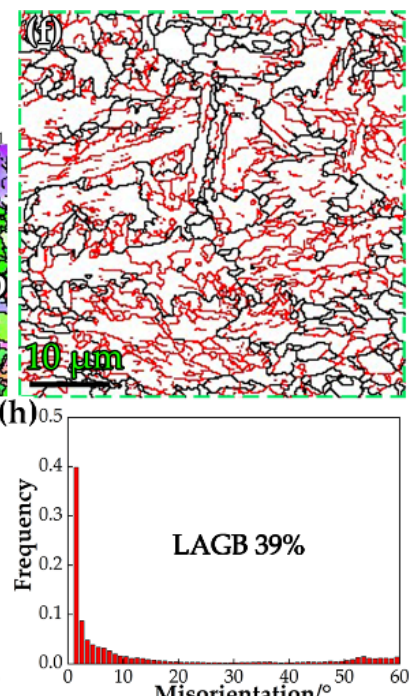

Figure 13. EBSD analysis of the specimens obtained from surface and mid-thickness region in steel A plate. (a,e) orientation image map, (b,f) image quality map with grain boundary misorientation, $(\mathbf{c}, \mathbf{g})$ grain diameter distribution, and $(\mathbf{d}, \mathbf{h})$ misorientation distribution.

Based on Equation (1), the grain refinement strengthening has been calculated to be 235.3 and 222.1 MPa in the surface and mid-thickness region of steel A, while in steel $\mathrm{B}$, the grain refinement strengthening is 165.2 and $139.6 \mathrm{MPa}$. So, the main difference in yield strength for steel A and B should be attributed to grain refinement strengthening and precipitation strengthening. In addition, it is visible that UFC can unify the grain size and precipitate size, which guarantees the homogeneity of yield strength. In addition, the excellent impact toughness in steel A can be attributed to the high-volume fraction of LB and AF and the small polygonal ferrite grain, which have a strong ability to deflect the crack propagation. 
Above all, the mechanical properties in steel A are more homogeneous compared with that in steel $\mathrm{B}$, which can be attributed to the relatively uniform cooling rate in the newly developed UFC system.

\section{Conclusions}

(1) An excellent heavy steel plate has been obtained with a yield strength, tensile strength, and impact toughness of $-20{ }^{\circ} \mathrm{C}$ of $592 \mathrm{MPa}, 720 \mathrm{MPa}$, and $75 \mathrm{~J}$, which is mainly devoted to grain refinement strengthening and precipitation strengthening.

(2) The microstructure and mechanical properties of the heavy steel plate produced by UFC are more uniform compared with that by traditional accelerated cooling, for the cooling rate of UFC is uniform along the longitudinal direction of the thick plate.

(3) The crystallographic characteristic of precipitates has been analyzed. The size of austenite strain-induced $\mathrm{TiC}$ is relatively large, and obeys the $\mathrm{KS}$ orientation relationship with the ferrite matrix, while for TiC formed in the supersaturated ferrite, the size is less than $5 \mathrm{~nm}$, and obeys $[112]_{\mathrm{MC}} / /[110]_{\alpha}$ and $(\overline{112})_{\mathrm{MC}} / /(\overline{112})_{\alpha}$ orientation relationship with the ferrite matrix.

Author Contributions: Conceptualization, X.L. and X.D.; methodology, X.L.; formal analysis, X.L., Q.L. and H.L.; investigation, H.L. and Q.L.; resources, Z.W.; data curation, X.L. and X.D.; writingoriginal draft preparation, X.L.; writing-review and editing, X.L., X.G.; supervision, X.D., X.G; funding acquisition, Z.W. All authors have read and agreed to the published version of the manuscript.

Funding: This research was funded by the National Natural Science Foundation of China, grant number 52004224 and the China Postdoctoral Science Foundation grant number 2020M683559.

Institutional Review Board Statement: Not applicable.

Informed Consent Statement: Not applicable.

Data Availability Statement: Not applicable.

Conflicts of Interest: The authors declare no conflict of interest.

\section{References}

1. Funakawa, Y.; Shiozaki, T.; Tomita, K.; Yamamoto, T.; Maeda, E. Development of high strength hot-rolled sheet steel consisting of ferrite and nanometer-sized carbides. ISIJ Int. 2004, 44, 1945-1951. [CrossRef]

2. Shen, X.J.; Li, D.Z.; Chen, J.; Tang, S.; Wang, G.D. The Effect of Initial Microstructure on Microstructure Evolution and Mechanical Properties of Intercritically Rolled Low-Carbon Microalloyed Steel Plates. Steel Res. Int. 2019, 90, 1900237. [CrossRef]

3. Ye, Q.B.; Liu, Z.Y.; Yang, Y.; Wang, G.D. Effect of Rolling Temperature and Ultrafast Cooling Rate on Microstructure and Mechanical Properties of Steel Plate. Metall. Mater. Trans. A 2016, 47, 3622-3632. [CrossRef]

4. Li, X.L.; Lei, C.S.; Tian, Q.; Deng, X.T.; Chen, L.; Gao, P.L.; Du, K.P.; Du, Y.; Yu, Y.G.; Wang, Z.D.; et al. Nanoscale cementite and microalloyed carbide strengthened Ti bearing low carbon steel plates in the context of newly developed ultrafast cooling. Mater. Sci. Eng. A 2017, 698, 268-276. [CrossRef]

5. Li, X.L.; Wang, Z.D.; Deng, X.T.; Wang, G.D.; Misra, R.D.K. The Determining Role of Finish Cooling Temperature on the Microstructural Evolution and Precipitation Behavior in an Nb-V-Ti Microalloyed Steel in the Context of Newly Developed Ultrafast Cooling. Metall. Mater. Trans. A 2016, 47, 1929-1938. [CrossRef]

6. Shen, X.J.; Tang, S.; Chen, J.; Liu, Z.Y.; Wang, G.D. Improving Toughness of Heavy Steel Plate by Deformation Distribution Under Low Finish Cooling Temperature. J. Mater. Eng. Perform. 2016, 25, 3682-3690. [CrossRef]

7. Nishioka, K.; Ichikawa, K. Progress in thermomechanical control of steel plates and their commercialization. Sci. Technol. Adv. Mater. 2012, 13, 023001. [CrossRef]

8. Gladman, T. The Physical Metallurgy of Microalloyed Steels, 1st ed.; The Institute of Materials: London, UK, 1997.

9. Cheng, L.; Cai, Q.W.; Xie, B.S.; Ning, Z.; Zhou, X.C.; Li, G.S. Relationships among microstructure, precipitation and mechanical properties in different depths of Ti-Mo low carbon low alloy steel plate. Mater. Sci. Eng. A 2016, 651, 185-191. [CrossRef]

10. Tang, S.; Liu, Z.Y.; Wang, G.D. Microstructural evolution and mechanical properties of high strength microalloyed steels: Ultra-Fast Cooling (UFC) versus Accelerated Cooling (ACC). Mater. Sci. Eng. A 2013, 580, 257-265. [CrossRef]

11. Li, X.L.; Lei, C.S.; Deng, X.T.; Wang, Z.D.; Yu, Y.G.; Wang, G.D.; Misra, R.D.K. Precipitation strengthening in titanium microalloyed high-strength steel plates with new generation-thermomechanical controlled processing (NG-TMCP). J. Alloy. Compd. 2016, 689, 542-553. [CrossRef]

12. Kim, Y.W.; Hong, S.G.; Huh, Y.H.; Lee, C.S. Role of rolling temperature in the precipitation hardening characteristics of Ti-Mo microalloyed hot-rolled high strength steel. Mater. Sci. Eng. A 2014, 615, 255-261. [CrossRef] 
13. Tang, S.; Liu, Z.Y.; Wang, G.D. Development of High Strength Plates with Low Yield Ratio by the Combination of TMCP and Inter-Critical Quenching and Tempering. Steel Res. Int. 2011, 82, 772-778. [CrossRef]

14. Hu, J.; Du, L.X.; Xie, H.; Gao, X.H.; Misra, R.D.K. Microstructure and mechanical properties of TMCP heavy plate microalloyed steel. Mater. Sci. Eng. A 2014, 607, 122-131. [CrossRef]

15. Uemori, R.; Hasegawa, Y.; Hara, T.; Inoue, T.; Shinohara, Y.; Inoue, H.; Furuya, H. Steels for energy production and transport. Nippon Steel Technical Report. Nippon Steel Tech. Rep. 2012, 101, 68-78.

16. Nie, Y.; Shang, C.J.; Song, X.; You, Y.; Li, C.; He, X.L. Properties and homogeneity of 550-MPa grade TMCP steel for ship hull. Int. J. Miner. Metall. Mater. 2010, 17, 179-184. [CrossRef]

17. Liu, D.; Cheng, B.; Chen, Y. Strengthening and Toughening of a Heavy Plate Steel for Shipbuilding with Yield Strength of Approximately 690 MPa. Metall. Mater. Trans. A 2013, 44, 440-455. [CrossRef]

18. Cao, Z.Q.; Bao, Y.P.; Xia, Z.H.; Luo, D.; Guo, A.M.; Wu, K.M. Toughening mechanisms of a high-strength acicular ferrite steel heavy plate. Int. J. Miner. Metall. Mater. 2010, 17, 567-572. [CrossRef]

19. Wang, B.; Liu, Z.Y.; Zhang, X.G.; Wang, G.D.; Misra, R.D.K. Precipitation behavior of nanoscale cementite in hypoeutectoid steels during ultra fast cooling (UFC) and their strengthening effects. Mater. Sci. Eng. A 2013, 575, 189-198. [CrossRef]

20. Zhao, M.C.; Huang, X.F.; Atrens, A. Role of second phase cementite and martensite particles on strength and strain hardening in a plain C-Mn steel. Mater. Sci. Eng. A 2012, 549, 222-227. [CrossRef]

21. Fu, J.; Li, G.; Mao, X.; Fang, K.M. Nanoscale Cementite Precipitates and Comprehensive Strengthening Mechanism of Steel. Metall. Mater. Trans. A 2011, 42, 3797-3812. [CrossRef]

22. Bu, F.Z.; Wang, X.M.; Chen, L.; Yang, S.W.; Shang, C.J.; Misra, R.D.K. Influence of cooling rate on the precipitation behavior in Ti-Nb-Mo microalloyed steels during continuous cooling and relationship to strength. Mater. Charact. 2015, 102, 146-155. [CrossRef]

23. Opiela, M.; Grajcar, A. Microstructure and Anisotropy of Plastic Properties of Thermomechanically-Processed HSLA-Type Steel Plates. Metals 2018, 8, 304. [CrossRef]

24. Grajcar, A.; Morawiec, M.; Zalecki, W. Austenite Decomposition and Precipitation Behavior of Plastically Deformed Low-Si Microalloyed Steel. Metals 2018, 8, 1028. [CrossRef]

25. Hu, J.; Du, L.X.; Wang, J.J.; Gao, C.R. Effect of welding heat input on microstructures and toughness in simulated CGHAZ of V-N high strength steel. Mater. Sci. Eng. A 2013, 577, 161-168. [CrossRef]

26. Yong, Q.L.; Ma, M.T.; Wu, B.R. Microalloyed Steel-Physical and Mechanical Metallurgy, 1st ed.; Mechanical Industry Press: Beijing, China, 1989.

27. Huang, X.Y. The Microstructure of Materials and Its Electron Microscopy Analysis, 1st ed.; Metallurgical Industry Press: Beijing, China, 2008.

28. Yen, H.W.; Huang, C.Y.; Yang, J.R. The Nano Carbide Control: Design of Super Ferrite in Steels. Adv. Mater. Res. 2010, 8-91, 663-668. [CrossRef]

29. Li, X.L.; Jin, C.; Li, H.Z.; Hao, X.X.; He, Y.; Deng, X.T.; Wang, Z.D. Influence of cooling rate on phase transformation and precipitation behavior of Ti-bearing steel in continuous cooling process. J. Iron Steel Res. Int. 2021, in press. [CrossRef]

30. Wan, X.L.; Wu, K.M.; Huang, G.; Nune, K.C.; Li, Y.; Cheng, L. Toughness improvement by Cu addition in the simulated coarse-grained heat-affected zone of high-strength low-alloy steels. Sci. Technol. Weld. Join. 2016, 21, 295-302. [CrossRef] 